\title{
Anomalous coronary arteries from the opposite sinus of Valsalva in asymptomatic siblings treated with pulmonary arterial translocation
}

\author{
Derek Y. Obayashi, MD, ${ }^{a}$ Jay Yeh, MD, ${ }^{b}$ Norman H. Silverman, MD, ${ }^{a}$ and Frank L. Hanley, MD, ${ }^{c}$ \\ Stanford and Oakland, Calif
}

Familial presentation of anomalous coronary arteries (ACAs) from an inappropriate sinus of Valsalva has been reported rarely in the literature. Of the few reports in adults,

From the Division of Pediatric Cardiology, ${ }^{\text {a }}$ Stanford University School of Medicine, Stanford, Calif; the Department of Pediatrics, ${ }^{\mathrm{b}}$ Children's Hospital and Research Center Oakland, Oakland, Calif; and the Department of Cardiothoracic Surgery, ${ }^{c}$ Stanford University School of Medicine, Stanford, Calif.

Received for publication July 25, 2008; revisions received May 7, 2010; accepted for publication May 16, 2010

Address for reprints: Norman H. Silverman, MD, Division of Pediatric Cardiology, Lucile Packard Children's Hospital, Stanford University Medical Center, 750 Welch Rd, Suite 305, Palo Alto, CA 94304 (E-mail: Norm_Silverman@Stanford.edu).

J Thorac Cardiovasc Surg 2010;140:1430-2

$0022-5223 / \$ 36.00$

Copyright (c) 2010 by The American Association for Thoracic Surgery

doi:10.1016/j.jtcvs.2010.05.012 none involves asymptomatic patients. ${ }^{1}$ Only 1 case involving asymptomatic children has been reported. ${ }^{2}$ We report pulmonary artery translocation in 2 asymptomatic brothers with interarterial ACAs arising from the inappropriate sinus.

\section{CLINICAL SUMMARIES \\ Patient 1}

A 4-year-old asymptomatic boy with a murmur received a diagnosis of coronary cameral fistula by echocardiogram. Angiography at catheterization for coil embolization demonstrated an anomalous left main coronary artery (LMCA) arising from the right sinus of Valsalva. Repeat echocardiography showed this anomaly with the artery coursing between the great vessels before bifurcating into
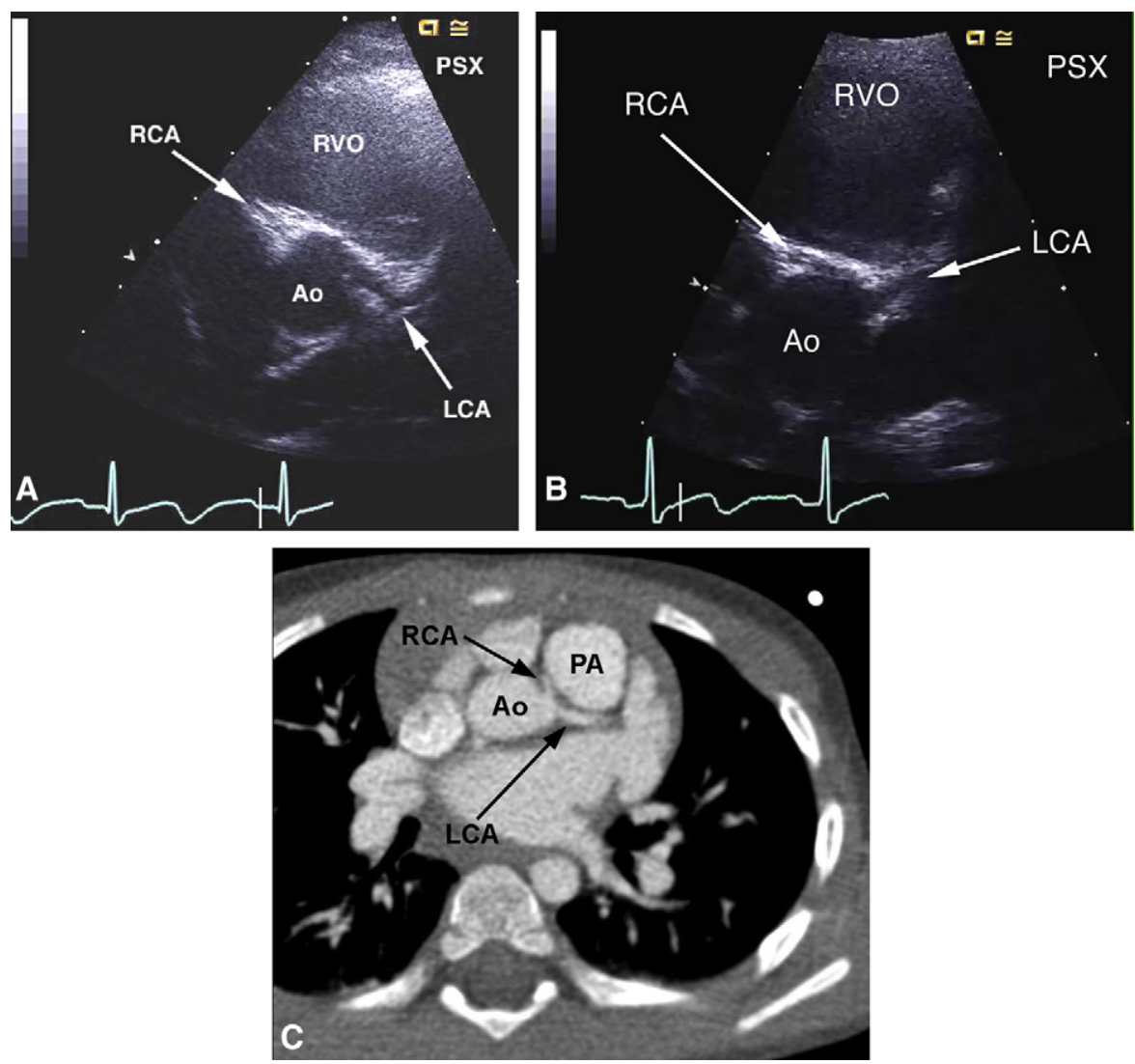

FIGURE 1. Diagnostic imaging of siblings with anomalous coronary arteries. A, Echocardiogram of patient 1 demonstrating anomalous left coronary artery $(L C A)$ from the right coronary sinus with single origin. B, Echocardiogram of patient 2 showing anomalous right coronary artery $(R C A)$ from the left coronary sinus with single origin. C, Computed tomographic scan of patient 2 confirming echocardiographic findings. Ao, Aorta; $R V O$, right ventricular ouflow; PSX, parasternal short axis view; $P A$, pulmonary artery. 

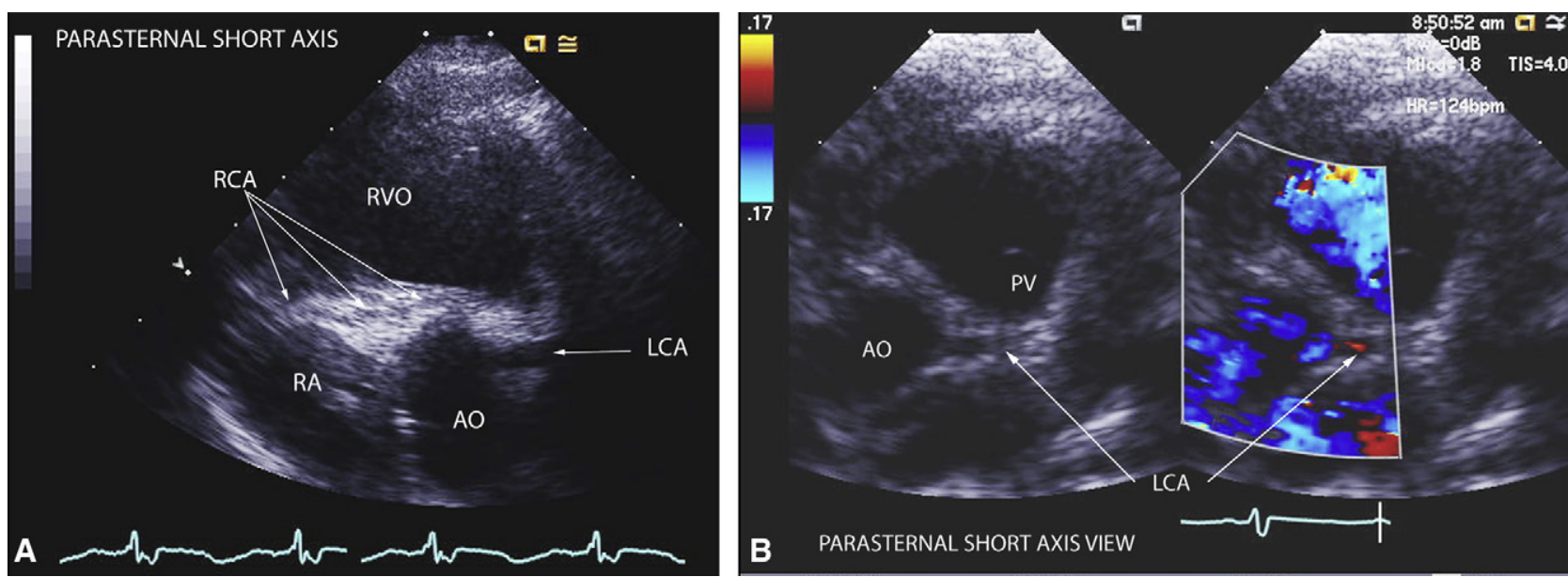

FIGURE 2. A, Parasternal short-axis view after operation on sibling 1 taken before postoperative discharge. The left coronary artery $(L C A)$ originates without an intramural course from the aorta, $(A O)$. The origin and course of the right coronary artery $(R C A)$ are noted by arrows. The right atrium $(R A)$ and right ventricular outflow $(R V O)$ are labeled. $\mathrm{B}$, A cross-sectional image (left) and superimposed Doppler color-flow information (right) done before discharge of sibling 2 after translocation of the right pulmonary artery. Comparison with the echocardiogram and computed tomographic scan show the right coronary artery lying away from the pulmonary artery and the pulmonary valve $(P V)$. The left coronary artery $(L C A)$ is also indicated by an arrow. Both children are still well and asymptomatic 5 and 4 years after surgery was performed. $H R$, Heart rate.

left anterior descending and circumflex coronary arteries (Figure 1,A). At surgery, the right and left coronary arteries were found rising from a common ostium in the right coronary sinus with no intramural component. Consequently, the right pulmonary artery was translocated by the LeCompte maneuver; the proximal main pulmonary artery (MPA) was placed anteriorly and away from the aortic root, allowing the LMCA to pass with no potential compression by the great vessels. Postoperative echocardiography showed normal heart function and unobstructed flow in the pulmonary and coronary arteries (Figure 2, A). The patient was discharged home without complication and remains asymptomatic.

\section{Patient 2}

The parents and 2 younger siblings were asymptomatic and underwent screening echocardiograms. The 6-monthold brother was found to have an anomalous right coronary artery arising from the left coronary sinus of Valsalva, with an interarterial course and single ostium without an intramural component (Figure 1,B). Computed tomography at 17 months of age confirmed these findings (Figure 1, C). At 3 years of age and weighing $14 \mathrm{~kg}$, he underwent translocation of the MPA toward the left hilum of the transverse pulmonary artery. Surgical separation of the proximal MPA from the aorta created an unobstructed gap for the anomalous right coronary artery to pass between both great vessels (Figure 2, B). Follow-up test results were within normal limits and the patient was discharged home after an uneventful postoperative course. He remains asymptomatic.

\section{DISCUSSION}

Familial clustering has recently been reported in children, and its discussion is one of the purposes of this report. ${ }^{2}$ Laureti, Singh, and Blankenship ${ }^{1}$ reported 1 case and cited others of adults experiencing cardiovascular symptoms including palpitations, angina, and chest pain before discovery of the ACA. None were preemptively screened after diagnosis of their first-degree relative. To our knowledge, this is the first published report of a diagnosis made by screening echocardiography in an asymptomatic relative who underwent operative repair.

True prevalence of ACAs arising from opposite coronary sinuses is unknown and diagnosis is often incidental during angiography, echocardiography, or necroscopy. Yamanaka and $\mathrm{Hobbs}^{3}$ found that $1.3 \%$ of all patients undergoing coronary angiography have ACAs and estimated an overall incidence of $0.1 \%$. Davis and associates ${ }^{4}$ reported an incidence of $0.17 \%$ in asymptomatic children and adolescents. Sudden death without preceding ischemic symptoms is frequently encountered in the pediatric population. ${ }^{5}$ Furthermore, the risk for sudden death is highest in younger patients with an ACA coursing between the aorta and pulmonary trunk. ${ }^{6}$

Our institutional policy is that when an ACA is found to arise from the opposite coronary sinus, surgical repair is usually warranted in the preadolescent period whether or not clinical symptoms exist. ${ }^{6}$ If the ACA originates from the opposite sinus as a separate ostium, coronary reimplantation to the appropriate sinus is preferred. Intramural segments are unroofed and ostial translocations are performed if coronary anatomy is favorable. When an ACA originates from the opposite sinus as a single ostium 
with interarterial course and no intramural component, we favor pulmonary artery translocation to create space between the aortic and pulmonic roots, thereby decreasing the risk of pulmonary compression of the coronary artery. ${ }^{7}$ Intraoperative inspection determines which procedure will be performed. If the orientation of the aortic and pulmonic roots is such that anterior movement of the MPA will create space, a LeCompte maneuver is done. Alternatively, if moving the MPA laterally will create space, the MPA is translocated distally toward the left pulmonary artery.

At the current time there is not sufficient data to form firm management guidelines for asymptomatic children with ACAs from the contralateral sinus. Because of the documented risk of sudden death without antecedent symptoms, our policy is to surgically correct all lesions at risk, regardless of symptoms. Although we believe pulmonary artery translocation is protective of subsequent ischemic episodes, long-term follow-up has not been achieved. Whether it will reduce subsequent risk of myocardial ischemia or sudden cardiac death remains to be determined.

\section{References}

1. Laureti JM, Singh K, Blankenship J. Anomalous coronary arteries: a familial clustering. Clin Cardiol. 2005;28:488-90.

2. Brothers JA, Stephens P, Gaynor JW, Lorber R, Vricella LA, Paridon SM. Anomalous aortic origin of a coronary artery with an interarterial course: should family screening be routine? J Am Coll Cardiol. 2008;51:2062-4.

3. Yamanaka O, Hobbs RE. Coronary artery anomalies in 126,595 patients undergoing coronary arteriography. Cathet Cardiovasc Diagn. 1990;21:28-40.

4. Davis JA, Cecchin F, Jones TK, Portman MA. Major coronary artery anomalies in a pediatric population: incidence and clinical importance. J Am Coll Cardiol. 2001;37:593-7

5. Taylor AJ, Rogan KM, Virmani R. Sudden cardiac death associated with isolated congenital coronary artery anomalies. J Am Coll Cardiol. 1992;20:640-7.

6. Gulati R, Reddy VM, Culbertson C, Helton G, Suleman S, Reinhartz O, et al. Surgical management of coronary artery arising from the wrong coronary sinus, using standard and novel approaches. J Thorac Cardiovasc Surg. 2007;134:1171-8.

7. Rodefeld MD, Culbertson CB, Rosenfeld HM, Hanley FL, Thompson LD. Pulmonary artery translocation: a surgical option for complex anomalous coronary artery anatomy. Ann Thorac Surg. 2001;72:2150-2.

\title{
Quadruple valve replacement in patients with carcinoid heart disease
}

\author{
Arman Arghami, MD, ${ }^{\mathrm{a}}$ Heidi M. Connolly, MD, ${ }^{\mathrm{b}}$ Martin D. Abel, MD, ${ }^{\mathrm{c}}$ and Hartzell V. Schaff, MD, ${ }^{\mathrm{a}}$ \\ Rochester, Minn
}

Carcinoid is a rare tumor of neuroendocrine cell lineage that occurs in 1.2 to 2.1 persons per 100,000 per year. ${ }^{1}$ At diagnosis, $20 \%$ to $30 \%$ of patients have disseminated disease and consequent carcinoid syndrome. ${ }^{2}$ Carcinoid heart disease affects $40 \%$ of patients and remains a source of major morbidity and mortality in carcinoid syndrome. Heart involvement is thought to occur when serotonin and other active substances are released from hepatic metastases or primary ovarian carcinoid tumors, thus bypassing metabolism in the liver.

Carcinoid heart disease typically involves tricuspid and pulmonary valves, and patients often present with signs and symptoms of right heart failure. Left-sided valve involvement is reported infrequently $(<10 \%$ of patients with carcinoid heart disease $)^{1}$ and is possibly due to metabolism of active substances by the lung. Thus, carcinoid

From the Divisions of Cardiovascular Surgery, ${ }^{\text {a }}$ Cardiovascular Diseases, ${ }^{\text {b }}$ and Cardiovascular and Thoracic Anesthesia, ${ }^{\mathrm{c}}$ Mayo Clinic, Rochester, Minn.

Disclosures: None.

Received for publication Feb 11, 2010; revisions received April 14, 2010; accepted for publication May 14, 2010; available ahead of print June 28, 2010.

Address for reprints: Hartzell V. Schaff, MD, Division of Cardiovascular Surgery,

Mayo Clinic, 200 First St SW, Rochester MN 55905 (E-mail: schaff@ mayo.edu).

J Thorac Cardiovasc Surg 2010;140:1432-4

$0022-5223 / \$ 36.00$

Copyright (C) 2010 by The American Association for Thoracic Surgery

doi:10.1016/j.jtcvs.2010.05.026 disease of the mitral and aortic valves may occur more frequently in patients with an atrial septal defect or patent foramen ovale (PFO) with right-to-left shunting of blood. Left heart involvement may also occur in the absence of an intracardiac shunt, perhaps with bronchopulmonary carcinoid or high levels of circulating serotonin. ${ }^{3}$ We describe our experience with 7 patients who, because of carcinoid heart disease, underwent quadruple valve replacement.

\section{CLINICAL SUMMARY}

Between July 1989 and April 2010, 7 patients underwent quadruple valve replacement for carcinoid heart disease at Mayo Clinic, Rochester, Minnesota. This group comprised $4 \%$ of 168 patients who had valve surgery for carcinoid heart disease and $23 \%$ of the 30 patients with concomitant involvement of the mitral or aortic valves.

\section{RESULTS}

All patients had clinical signs and symptoms of right and left heart failure and echocardiographic evidence of carcinoid heart disease, including thickened valves with regurgitation. Right-sided valves had more severe involvement than left except for 1 patient who had moderate tricuspid regurgitation and severe regurgitation affecting the 3 other valves. Intraoperative echocardiography identified a PFO 